\title{
Asthma symptoms do not predict spirometry
}

\author{
Robert L Cowie MD, Margot F Underwood BN, Stephen K Field MD
}

\begin{abstract}
RL Cowie, MF Underwood, SK Field. Asthma symptoms do not predict spirometry. Can Respir J 2007;14(6):339-342.
\end{abstract}

BACKGROUND: Asthma is a disease characterized by variable airflow obstruction, but the measurement of airflow is often omitted in the process of diagnosis and management of the disease.

OBJECTIVES: Features of asthma severity and control were examined to determine the extent to which objective measurements, including forced expiratory volume in $1 \mathrm{~s}$ and forced expiratory volume in $1 \mathrm{~s} /$ forced vital capacity, correlated with other manifestations of the disease.

METHODS: Subjects were a consecutive sample of patients with asthma attending a university-based asthma clinic. All subjects underwent routine assessment using a standard questionnaire and spirometry. RESULTS: A total of 500 subjects were included in the present study, and their assessment showed that neither symptoms nor history could predict or be predicted by their measurements of lung function.

CONCLUSION: Routine measurement of lung function should be performed on subjects with asthma if normal or near-normal lung function is a desired component of asthma control.

Key Words: Asthma; Control; FEV ${ }_{1}$; Spirometry; Symptoms sthma control and severity have conventionally been Aassessed using several indices, which have usually included symptoms, level of treatment and lung function $(1,2)$. In clinical practice and in epidemiological studies $(3,4)$, it is common not to use objective measures of airflow obstruction but to rely on symptoms to assess disease control; however, some reports (5) show that there may be a poor correlation between asthma symptoms and lung function measurements. In many instances, the discrepancy between these components is striking, and it has been proposed that the most abnormal feature be used to categorize the severity of asthma (6). Patients with asthma with similar levels of lung function may experience a wide range of symptoms and morbidity. There are data that suggest that symptom awareness and airway obstruction are inversely related (7); thus, it is possible that a patient who is well-controlled by symptom criteria might, in fact, have severe and poorly controlled disease. In the present study, we examined the relationship among symptom control, self-assessed lifestyle restriction, level of therapy and spirometry in asthma.

\section{METHODS}

To assess the relationship among asthma symptoms, components of asthma control and asthma severity, and the measurements of airway obstruction using spirometry, these elements were examined in patients attending the Asthma

\section{Les symptômes d'asthme : non prédictifs de la spirométrie}

CONTEXTE : L'asthme est une maladie qui se caractérise par une obstruction plus ou moins grande des voies aériennes, mais on néglige souvent de mesurer l'écoulement de l'air au moment de l'établissement du diagnostic et dans la prise en charge de la maladie.

BUT : L'étude consistait en un examen des critères de gravité et de maîtrise de l'asthme pour déterminer jusqu'à quel point les mesures objectives, notamment le volume expiratoire maximal par seconde et le rapport volume expiratoire maximal par seconde/capacité vitale maximale, étaient en corrélation avec d'autres manifestations de la maladie.

MÉTHODE : L'échantillon a été constitué de sujets asthmatiques consécutifs, vus en consultation dans un centre universitaire du traitement de l'asthme. Tous les sujets ont été soumis à l'évaluation habituelle à l'aide d'un questionnaire usuel et de la spirométrie.

RÉSULTATS : Cinq cents sujets, au total, ont participé à l'étude et il est ressorti de leur évaluation que ni les symptômes ni les antécédents ne pouvaient servir de prédicteurs du fonctionnement pulmonaire, ni l'inverse d'ailleurs.

CONCLUSION : Il faudrait procéder à une mesure régulière du fonctionnement pulmonaire chez les asthmatiques si le fonctionnement normal ou quasi normal des poumons faisait partie des critères de maîtrise de la maladie.

Clinic of the Calgary COPD and Asthma Program at the University of Calgary, Calgary, Alberta. All of the patients were referred by physicians and had a current diagnosis of asthma. Each patient completed a questionnaire, which contained questions about their asthma control, asthma medications and a self-assessment of the extent to which asthma restricted their lifestyle. This questionnaire has been used in our centre to assess more than 6000 individuals with the disease. The data obtained from the questionnaire appear to correlate well with other findings related to asthma severity and control (8). The questions asked included the following direct questions about asthma control:

- Beta -agonist use: "On average, how many doses of your bronchodilator (reliever medication) (Ventolin, Bricanyl, salbutamol, Berotec) do you use per day?"

- Waking at night: "In the past week, how many nights has your sleep been disturbed by asthma?"

- Emergency department visits: "Have you been to an emergency room or to a physician for urgent treatment of your asthma (for example, nebulized Ventolin) in the past 12 months?"

- Missed work or school: "Have you missed school or work because of asthma in the past three months?" 


\section{TABLE 1}

\section{Definitions of asthma control}

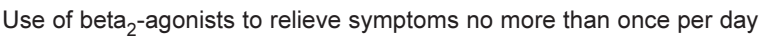

Not waking at night with asthma in the past week

No emergency treatment for asthma in the past year

No days off work or school for asthma in the past three months

TABLE 2

Characteristics of the $\mathbf{5 0 0}$ patients

\begin{tabular}{lc}
\hline Characteristics & \\
\hline Age, years, mean \pm SD & $41 \pm 15.7$ \\
Female to male ratio & $1.8: 1$ \\
Duration of asthma, years, mean \pm SD & $18 \pm 15.1$ \\
FEV $1 \%$ mean \pm SD & $80 \pm 20.5$ \\
FEV $/$ FVC\%, mean \pm SD & $72 \pm 11.9$ \\
Current smokers, $n(\%)$ & $63(13)$ \\
Ex-smokers, n (\%) & $165(33)$ \\
Household animals, $n(\%)$ & $247(49)$ \\
Use of inhaled corticosteroid, $n(\%)$ & $360(72)$ \\
Use of daily prednisone, $n(\%)$ & $8(1.6)$ \\
Used prednisone more than two courses/year, n (\%) & $40(8)$ \\
\hline
\end{tabular}

FEV $1 \%$ Forced expiratory volume in $1 \mathrm{~s}$ expressed as a percentage of predicted; FEV $1 / F V C \%$ Ratio of FEV 1 and forced vital capacity expressed as a percentage

Additional questions were asked in relation to the patient's medication, including their use of inhaled and oral corticosteroid, asthma monitoring, use of action plans, hospital admissions and asthma trigger exposure.

The patients who had been asked to withhold their bronchodilator medication for at least $4 \mathrm{~h}$ performed spirometry before and after use of a bronchodilator. Spirometry was performed by a trained operator using the American Thoracic Society criteria (9) for acceptability and an appropriate spirometer, which was calibrated each day. A respirologist then assessed each patient to determine whether they did have asthma and to make adjustments to their medication. In the event there was doubt about the diagnosis, the physician requested either a methacholine challenge test or an assessment of peak expiratory flow variability by morning and evening measurements of peak expiratory flow over several weeks. With the patient's written permission, relevant details concerning those patients considered to have asthma were then entered into a database. In the database, the daily dose of inhaled corticosteroid was converted into beclomethasone equivalent, and a field was created to indicate whether the patient did or did not conform with the definition of disease control. Asthma control was broadly based on the Canadian Asthma Consensus Report (2) and was defined as being the absence of nighttime wakening with asthma in the past week, the need to use short-acting beta 2 -agonist no more than once per day for relief of symptoms, no visits for emergency treatment of asthma in the previous year and no time missed from work or school in the past three months (Table 1). The patient's self-assessment of the impact of asthma on their lifestyle was made by asking the question: "On average, during the past month, to what extent has asthma modified or restricted your lifestyle?" on a scale from 1 to 10, with 10 indicating severe restriction and 1 no effect at all (8).

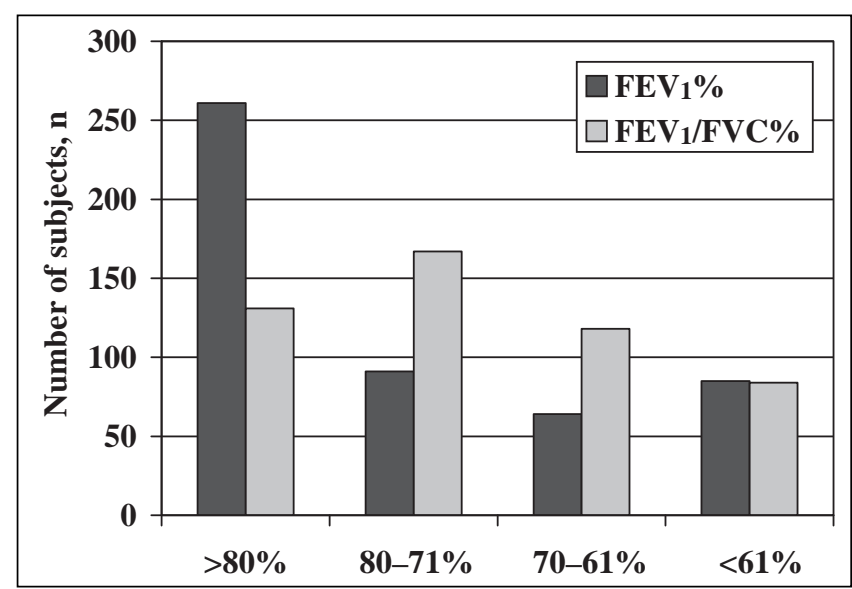

Figure 1) Distribution of forced expiratory volume in $1 \mathrm{~s}(\mathrm{FEV}) \%$ and $\mathrm{FEV}_{1} /$ Forced vital capacity (FVC)\%. $\mathrm{FEV}_{1} \%$ is the $\mathrm{FEV}_{1}$ expressed as a percentage of predicted (9); FEV $/ F V C \%$ is the ratio of $\mathrm{FEV}_{1}$ and $\mathrm{FVC}$ expressed as a percentage

Approval had previously been obtained from the Conjoint Health Research Ethics Board of the University of Calgary to maintain a database of our patients with asthma.

\section{Analysis}

Continuous data were analyzed using the Student's $t$ test or ANOVA, as well as by linear regression. A $\chi^{2}$ analysis was used for categorical data. The statistical analysis was performed using Epi Info 6 (Centers for Disease Control and Prevention, USA; World Health Organization, Switzerland).

\section{RESULTS}

The last 500 patients entered into the database were included in the present study. The average $( \pm$ SD) age of the subjects was $41 \pm 15.7$ years, and 321 patients were women. The average duration of their asthma was $18 \pm 15.1$ years. Asthma control, as defined in Table 1, had been achieved by 110 (22\%) subjects. A total of 360 patients reported a current use of inhaled corticosteroid. All of the 500 subjects had completed spirometry. Their forced expiratory volume in $1 \mathrm{~s}\left(\mathrm{FEV}_{1}\right) /$ forced vital capacity (FVC) expressed as a percentage was $72 \pm 11.9 \%$ and mean $\mathrm{FEV}_{1}$ expressed as a percentage of predicted (10) was $80 \pm 20.5 \%$. The patients' characteristics are presented in Table 2. The distribution of their $\mathrm{FEV}_{1} \%$ and $\mathrm{FEV}_{1} / \mathrm{FVC} \%$ is presented in Figure 1.

Neither $\mathrm{FEV}_{1} \%$ nor $\mathrm{FEV}_{1} / \mathrm{FVC} \%$ varied with the presence or absence of asthma control ( $\mathrm{P}>0.1)$. On examining the individual elements of our definition of control, only the use of short-acting beta ${ }_{2}$-agonists more than once per day to relieve symptoms correlated with the $\mathrm{FEV}_{1} \%$ (77\% versus $83 \%$ ) $(\mathrm{P}=0.004)$ (Table 3$)$. Using the subject's stated daily dose of inhaled corticosteroid (none, low dose, moderate dose and high dose) as an index of severity, there was also no correlation with spirometry $(\mathrm{P}=0.3)$ (Table 4$)$. The patients' selfassessment of lifestyle restriction caused by their asthma correlated with asthma control $(\mathrm{P}<0.0001)$ and with inhaled corticosteroid dose $(\mathrm{P}=0.003)$, but not with the degree of obstruction assessed by the $\mathrm{FEV}_{1} \%$ or by the $\mathrm{FEV}_{1} / \mathrm{FVC} \%$ $(\mathrm{R}=0.05, \mathrm{P}>0.1) . \mathrm{FEV}_{1} \%$ and $\mathrm{FEV}_{1} / \mathrm{FVC} \%$ showed significant correlation with the patient's age (loss of $0.35 \%$ and $0.3 \%$, respectively, for each additional year of age; $\mathrm{P}<0.0001$ ), the 
TABLE 3

Spirometry and control of asthma in $\mathbf{5 0 0}$ patients

\begin{tabular}{lccc}
\hline Characteristics & $\begin{array}{c}\text { Yes FEV }_{1} \% \\
\text { (mean } \pm \text { SD) }\end{array}$ & $\begin{array}{c}\text { No FEV }_{1} \% \\
\text { (mean } \pm \text { SD) }\end{array}$ & P \\
\hline $\begin{array}{l}\text { Waking at night with } \\
\text { asthma in the past week }\end{array}$ & $80 \pm 20.4$ & $81 \pm 20.6$ & 0.8 \\
$\begin{array}{l}\text { Using beta } 2 \text {-agonists more than } \\
\text { once per day }\end{array}$ & $77 \pm 21.4$ & $83 \pm 19.5$ & 0.004 \\
$\begin{array}{l}\text { Had emergency treatment } \\
\text { in the past year }\end{array}$ & $79 \pm 19.1$ & $82 \pm 21.7$ & 0.09 \\
$\begin{array}{l}\text { Missed days from school } \\
\text { or work in the past three months }\end{array}$ & $80 \pm 19.7$ & $82 \pm 20.9$ & 0.4 \\
$\begin{array}{l}\text { Any of the above } \\
\text { (asthma not controlled) }\end{array}$ & $80 \pm 20.0$ & $83 \pm 22.0$ & 0.2 \\
\hline
\end{tabular}

$\overline{\text { FEV }}$ \% Forced expiratory volume in $1 \mathrm{~s}$ expressed as a percentage of predicted

age of onset of the asthma and the duration of their asthma (each $\mathrm{P}<0.001$ ). Sex also predicted $\mathrm{FEV}_{1} \%$ and $\mathrm{FEV}_{1} / \mathrm{FVC} \%$, with males having more obstruction than females $(\mathrm{P}=0.02)$. Overall, using a regression analysis, increasing age, male sex and smoking more than 10 pack-years were most predictive of the degree of obstruction. Factors that were not relevant included self-reported disease control, the patient's selfassessment of lifestyle restriction from asthma and their disease severity as judged by the dose of inhaled corticosteroid that they were using.

A total of 228 patients were current or ex-smokers. Of these patients, 141 (62\%) had smoked 10 pack-years or less. Separate analysis of these 141 smokers and ex-smokers, as well as the 272 nonsmokers, showed that they did not differ in the context of lung function, asthma symptoms and asthma control. There were, however, significant differences between the 87 ex-and current smokers of more than 10 pack-years, and the remainder of the subjects in relation to their $\mathrm{FEV}_{1}(73 \%$ versus $82 \% ; \mathrm{P}=0.0001)$ and $\mathrm{FEV}_{1} / \mathrm{FVC} \%(67 \%$ versus $73 \%$; $\mathrm{P}=0.0001)$. Current smokers were less likely than ex- and nonsmokers to have asthma control ( $11 \%$ versus $24 \% ; \mathrm{P}=0.03$ )

\section{DISCUSSION}

Asthma is a disease characterized by variable airflow obstruction (11). In many instances, the assessment and, indeed, the diagnosis of asthma, is made without objective measurements of lung function (12). This omission is presumably based on the assumption that the patients' report of symptoms, exacerbations and use of short-acting beta 2 -agonist to relieve symptoms is sufficient to assess the extent to which their disease is controlled. In the present study, we have demonstrated that no assessment of pulmonary function in asthma can be assumed without formal measurement.

Several studies $(6,13,14)$ have demonstrated the poor correlation between asthma symptoms and spirometry. An apparent loss of symptom perception as asthma control deteriorates is of considerable concern and should predicate the inclusion of objective measurements of airflow in those with asthma and a history of severe exacerbations (15-17). Nevertheless, asthma control in clinical and epidemiological studies $(3,4)$ is often assessed by reported symptoms, a history of beta 2 -agonist use, time off work or school, and exacerbations. Our study suggests
TABLE 4

Severity on the basis of inhaled corticosteroid dose and spirometry

\begin{tabular}{lccc}
\hline $\begin{array}{l}\text { Inhaled corticosteroid } \\
\text { (beclomethasone equivalent), } \\
\boldsymbol{\mu g} / \text { day }\end{array}$ & $\mathbf{n}$ & $\begin{array}{c}\mathrm{FEV}_{\mathbf{1}} \%^{*} \\
\text { (mean } \pm \text { SD) }\end{array}$ & $\begin{array}{c}\mathrm{FEV}_{\mathbf{1}} / \mathrm{FVC} \text { \% }^{*} \\
\text { (mean } \pm \text { SD) }\end{array}$ \\
\hline 0 & 140 & $82 \pm 19.7$ & $72 \pm 11.1$ \\
$1-500$ & 150 & $80 \pm 20.2$ & $71 \pm 12.1$ \\
$501-1000$ & 166 & $81 \pm 21.2$ & $73 \pm 11.8$ \\
$>1000$ & 44 & $75 \pm 20.9$ & $70 \pm 14.6$ \\
\hline
\end{tabular}

*There was no significant difference in the forced expiratory volume in $1 \mathrm{~s}$ $\left(F E V_{1}\right) \%(10)$ or $F E V_{1}$ /forced vital capacity (FVC)\% among the four categories of inhaled corticosteroid use $(P=0.3)$. FEV $\%$ is the $F E V_{1}$ expressed as a percentage of predicted; $F E V_{1} / F V C \%$ is the ratio of $F E V_{1}$ and FVC expressed as a percentage

that asthma control may be overestimated by these limited assessments. Including an $\mathrm{FEV}_{1}$ of $80 \%$ predicted or greater in the definition of asthma control reduced the number of patients with control in our study from 110 (22\%) to $61(12 \%)$. These findings appear to emphasize the importance of combining spirometry with symptoms and history in the regular assessment of our patients with asthma.

It is not clear why our data appear to differ from that of Juniper et al (18), who suggested in their study of 50 subjects that the $\mathrm{FEV}_{1}$ and the use of short-acting beta ${ }_{2}$-agonist do not contribute to the overall assessment of asthma control. In the present study, the omission of excessive use of short-acting

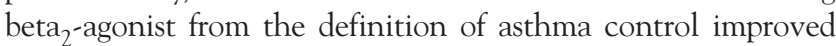
the proportion with disease control from 111 subjects to 148 . Excessive recent use of beta ${ }_{2}$-agonist seemed to be a relevant component of the definition of control, because it was associated with a history of emergency treatment for asthma in the preceding year $(\mathrm{P}=0.01)$. As noted, the inclusion of an $\mathrm{FEV}_{1}$ component to our definition of control decreased the number with disease control by $10 \%$. It would, thus, seem that in the present study, unlike that of Juniper et al (18), the inclusion of both the history of beta 2 -agonist use and a measurement of airway calibre make a significant contribution to the definition of disease control used in the Canadian asthma consensus report (2).

There is a clear relationship among asthma control, level of therapy (in particular, inhaled corticosteroid dose) and the patient's own assessment of the restriction on lifestyle imposed by asthma. This relationship suggests that these elements are valid indicators of asthma severity. However, in the present study, lung function tests, notably $\mathrm{FEV}_{1} \%$ and $\mathrm{FEV}_{1} / \mathrm{FVC} \%$, which reflect airway obstruction, show no relationship with these other measurements of asthma control or severity. This finding is clearly relevant because it demonstrates that it is not possible to estimate airway obstruction in patients with asthma on the basis of self-reported indices of control or the dose of inhaled corticosteroid used by patients. Measurements of airway obstruction appear to also be important for assessing risk for future asthma exacerbations: in studies of children (19) and of adolescents and adults (20) with asthma, the FEV expressed as a percentage of predicted showed an inverse relationship with the risk of future asthma attacks.

If normal or, at least, best lung function is one of the aims of asthma management, spirometry should be part of the regular assessment of patients with asthma, even in those who appear by the other criteria to have well-controlled disease. 


\section{REFERENCES}

1. Cockcroft DW, Swystun VA. Asthma control versus asthma severity. J Allergy Clin Immunol 1996;98:1016-8.

2. Boulet LP, Becker A, Bérubé D, Beveridge R, Ernst P. Canadian Asthma Consensus Report, 1999. Canadian Asthma Consensus Group. CMAJ 1999;161(11 Suppl):S1-61.

3. FitzGerald JM, Boulet LP, McIvor RA, Zimmerman S, Chapman KR. Asthma control in Canada remains suboptimal: The Reality of Asthma Control (TRAC) study. Can Respir J 2006;13:253-9.

4. Chapman KR, Ernst P, Grenville A, Dewland P, Zimmerman S. Control of asthma in Canada: Failure to achieve guideline targets. Can Respir J 2001;8(Suppl A):35A-40A.

5. Ståhl E. Correlation between objective measures of airway calibre and clinical symptoms in asthma: A systematic review of clinical studies. Respir Med 2000;94:735-41.

6. Colice GL, Burgt JV, Song J, Stampone P, Thompson PJ. Categorizing asthma severity. Am J Respir Crit Care Med 1999; 160:1962-7.

7. Bijl-Hofland ID, Folgering HT, van den Hoogen $\mathrm{H}$, et al. Perception of bronchoconstriction in asthma patients measured during histamine challenge test. Eur Respir J 1999;14:1049-54.

8. Cowie RL, Underwood MF, Revitt SG, Field SK. Predicting emergency room utilization in adults with asthma: A cohort study. J Asthma 2001;38:179-84.

9. American Thoracic Society. Standardization of Spirometry, 1994 Update. Am J Respir Crit Care Med 1995;152:1107-36.

10. Crapo RO, Morris AH, Gardner RM. Reference spirometric values using techniques and equipment that meet ATS recommendations. Am Rev Respir Dis 1981;123:659-64.
11. American Thoracic Society. Standards for diagnosis and care of patients with chronic obstructive pulmonary disease. Am J Respir Crit Care Med 1995;152:S77-S121.

12. Jin R, Choi BC, Chan BT, et al. Physician asthma management practices in Canada. Can Respir J 2000;7:456-65.

13. Shingo S, Zhang J, Reiss TF. Correlation of airway obstruction and patient-reported endpoints in clinical studies. Eur Respir J 2001;17:220-4.

14. Teeter JG, Bleecker ER. Relationship between airway obstruction and respiratory symptoms in adult asthmatics. Chest 1998;113:272-7.

15. Eckert DJ, Catcheside PG, Smith JH, Frith PA, McEvoy RD. Hypoxia suppresses symptom perception in asthma. Am J Respir Crit Care Med 2004;169:1224-30.

16. Eckert DJ, Catcheside PG, McEvoy RD. Blunted sensation of dyspnoea and near fatal asthma. Eur Respir J 2004;24:197-9.

17. Salome CM, Leuppi JD, Freed R, Marks GB. Perception of airway narrowing during reduction of inhaled corticosteroids and asthma exacerbation. Thorax 2003;58:1042-7.

18. Juniper EF, O'Byrne PM, Roberts JN. Measuring asthma control in group studies: Do we need airway calibre and rescue beta2-agonist use? Respir Med 2001;95:319-23.

19. Fuhlbrigge AL, Kitch BT, Paltiel AD, et al. FEV(1) is associated with risk of asthma attacks in a pediatric population. J Allergy Clin Immunol 2001;107:61-7.

20. Kitch BT, Paltiel AD, Kuntz KM, et al. A single measure of FEV1 is associated with risk of asthma attacks in long-term follow-up. Chest 2004;126:1875-82. 


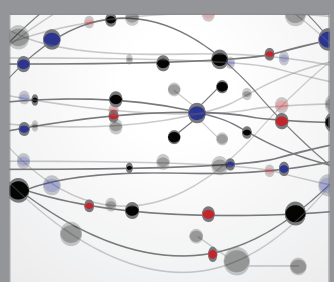

The Scientific World Journal
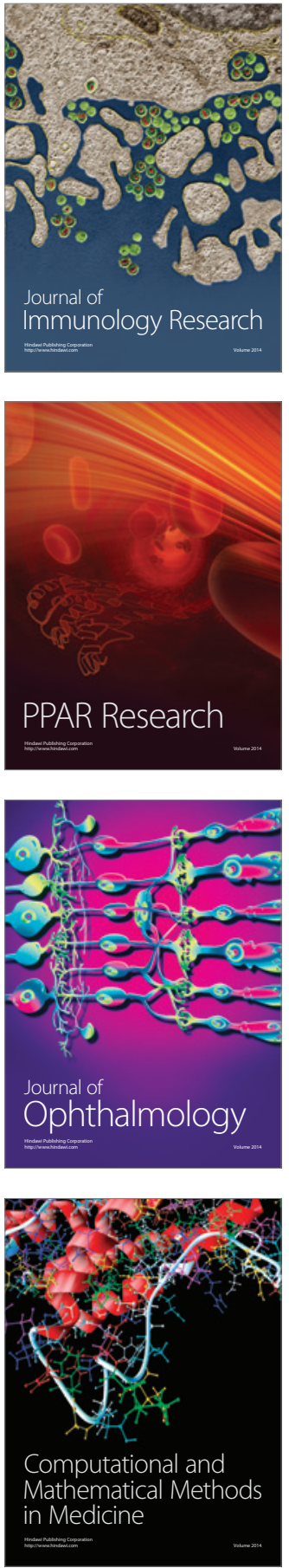

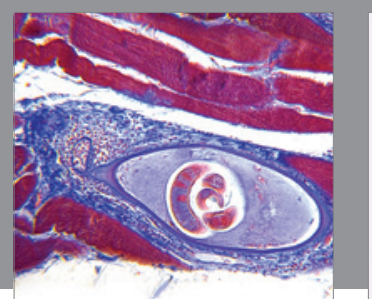

Gastroenterology Research and Practice

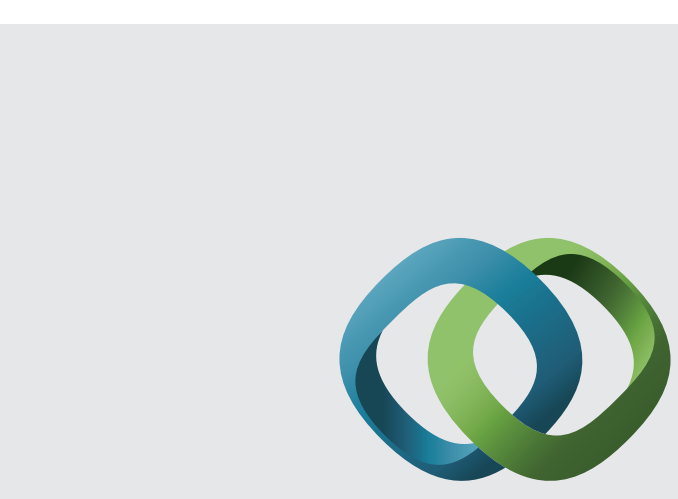

\section{Hindawi}

Submit your manuscripts at

http://www.hindawi.com
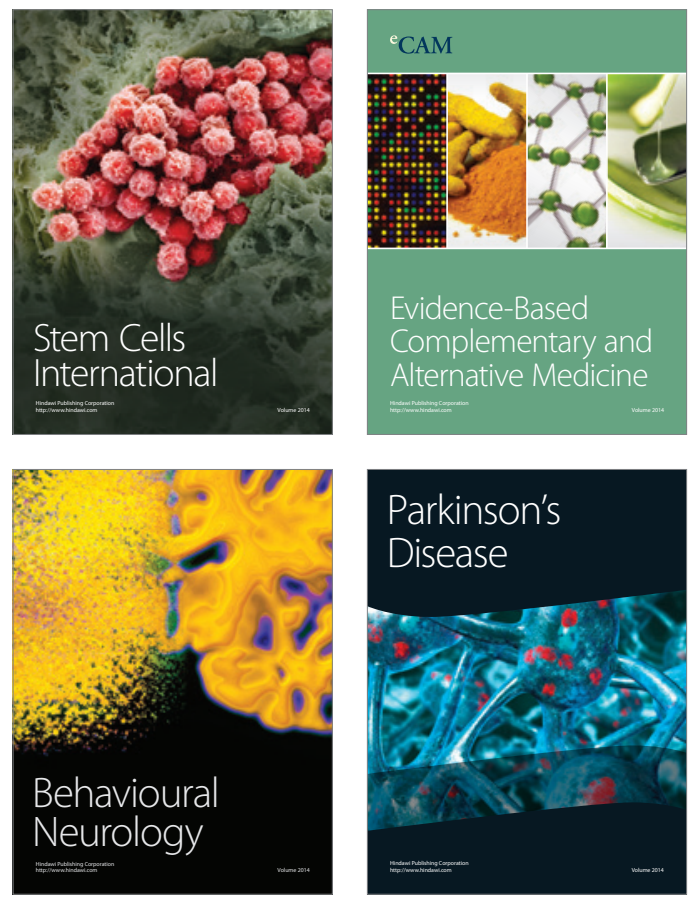
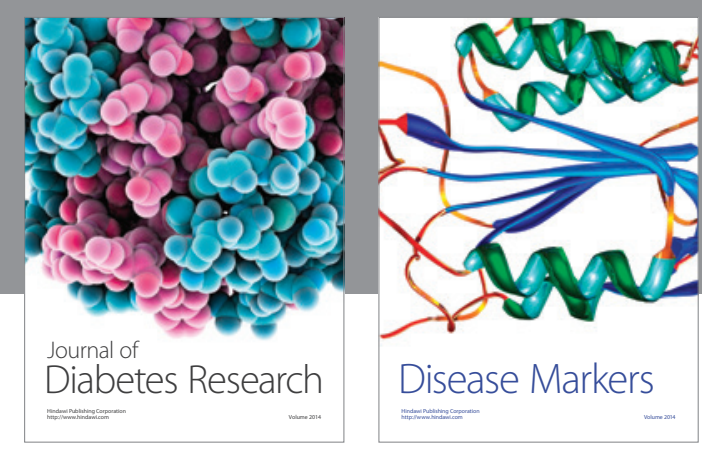

Disease Markers
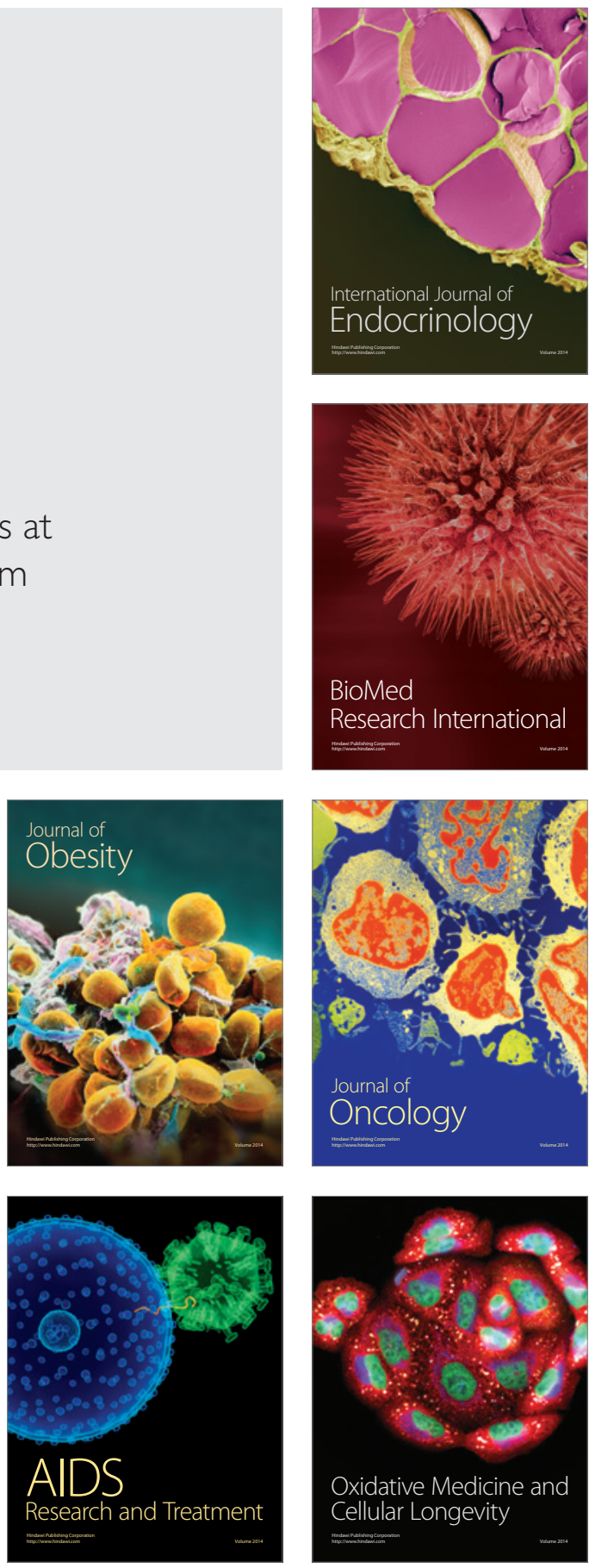